DOI: 10.21608/zvjz.2019.28652.

\title{
Macrolides and Fluoroquinolones Resistance Mechanisms in Campylobacters and their Incidence in Egypt; a Review Article
}

\author{
Ashraf A. Abd El Tawab ${ }^{1}$, Ahmed M. Ammar ${ }^{2}$, Heba A. Ahmed ${ }^{3}$, Ahmed A. Hefny ${ }^{4 *}$ \\ ${ }^{1}$ Bacteriology, Immunology and Mycology Department, Faculty of Veterinary Medicine, Benha \\ University, Egypt \\ ${ }^{2}$ Microbiology Department, Faculty of Veterinary Medicine, Zagazig University, 44511, Egypt \\ ${ }^{3}$ Zoonoses Department, Faculty of Veterinary Medicine, Zagazig University, 44511, Egypt \\ ${ }^{4}$ Veterinary Hospital, Faculty of Veterinary Medicine, Zagazig University, 44511, Egypt
}

\begin{abstract}
Campylobacter species are primarily zoonotic pathogens and recognized as a major cause of human illnesses. Poultry, especially, chicken is the main reservoir of Campylobacter species. The uncontrolled use of antibiotics in prophylaxis and treatment of animals caused an increase in antibiotic resistance to macrolides and fluoroquinolones (FQ) which are considered the drugs of choice for treatment of Campylobacter infection. Recently, studies suggested that multidrug efflux systems have the main role in lowering the efficacy of new and old antibiotics. Consequently, efforts are made to find suitable substances to reverse the action of the efflux pumps and prevent antimicrobial resistance. The substances used for evaluation of efflux pumps modulation are either efflux pump inhibitors (EPIs) or efflux pump inducers. The different types of EPIs; phenylalanine arginyl $\beta$-naphthylamide, verapamil and phenothiazines, of different mode of actions were used to suppress the activity of different types of efflux pumps. Aspirin, a drug in livestock and poultry, is a nonsteroidal anti-inflammatory, which induces non-heritable resistance of different bacteria to multiple antibiotics. Moreover, it also increases campylobacter resistance to antimicrobials. Alpha-tocopherol represents a new alternative approach against bacterial resistance. It shows modulatory activity on efflux system, showing clinically relevant results. Therefore, it is important to study different resistance mechanisms of campylobacters.
\end{abstract}

Keywords: Campylobacter spp., Antibiotic Resistance, Efflux Pump Inhibitors, $\alpha$-Tocopherol.

\section{Introduction}

Thermophilic Campylobacter species were implicated in several foodborne infections. $C$. jejuni is most frequently reported as a cause of human campylobacteriosis (80-90\%) compared to C. coli (5-10\%) [1]. Campylobacters are long spiral forms, curved, atypical Gram-negative rods [2], motile by means of a single polar unsheathed flagellum at one or both ends giving it the characteristic cork-screw motility [3]. All campylobacters grow mainly under microaerobic $\left(3-10 \% \mathrm{O}_{2}\right)$ and capnophilic conditions $\left(\begin{array}{lll}10 \% & \mathrm{CO}_{2}\end{array}\right)$ at $37^{\circ} \mathrm{C}$, but for the thermophilic species; $C$. jejuni, C. coli, C. lari, C. hyointestinalis subspp. hyointestinalis and $C$. upsaliensis the optimum temperature is $42^{\circ} \mathrm{C}$ [4]. This temperature is essential for growth adaptation in the intestines of warm-blooded birds and mammals [5]. Hippurate hydrolysis is the only phenotypic test differentiating $C$. jejuni from other species of campylobacters [6]. The two biotypes of $C$. jejuni are capable of hydrolyzing sodium hippurate to benzoic acid and glycine [7]. However, recently, false hippurate negative and positive $C$. jejuni strains have been reported in several studies [8-10]

The chicken gut especially the caeca is often colonized by campylobacters especially C. jejuni [1]. Consequently, chicken meat and products can be contaminated during processing and are considered the main source of campylobacteriosis in humans [11].

Campylobacteriosis in chickens is mainly a commensal infection [12]. It can infect chickens at young ages and defecation spreads the pathogen among the entire flock, but not before two weeks of age due to maternal antibody protection [13]. Once a bird is infected, the majority (>95\%) of the flock will be colonized by enteric campylobacters within several days and remain infected for life [14].

Campylobacters were recognized as a major cause of human illnesses ranging from acute diarrheal disease to sever illness; Guillain- 
Barre Syndrome [15]. They are naturally susceptible to several antimicrobial agents including fluoroquinolones (FQ) and macrolides which are considered the drugs of choice for infection treatment [16]. However, macrolide and FQ resistance, was recently documented to increase in several countries $[17,18]$. This is attributed to misuse of antibiotics in the animal husbandry and human population [19]. A unique restriction modification system which may decrease the uptake of foreign genetic material have been identified in Campylobacters, however, the acquisition of resistance genes from other microorganisms has been reported [20].
Therefore, studying different resistance mechanisms in Campylobacter spp. is important for human health.

\section{Antimicrobial resistance}

\section{Fluoroquinolones}

\section{Classification}

Quinolones are synthetic compounds with bactericidal activity. They became a widely used class of antimicrobials and divided into four groups according to their spectrum of activity (Table 1) [21].

Table 1: Four groups of fluoroquinolones based on their antimicrobial spectrum [21]

\begin{tabular}{ccc}
\hline Group & Antimicrobial spectrum & Antimicrobial agents (e.g.) \\
\hline $\mathbf{1}^{\text {st }}$ & & Cinoxacin \\
& Enterobacteriaceae & Nalidixic acid \\
& & Oxolinic acid \\
$\mathbf{2}^{\text {nd }}$ & $1^{\text {st }}$ group spectrum plus & Ciprofloxacin \\
& Pseudomonas aeruginosa, many & Norfloxacin \\
& Gram-positive cocci, Neisseria spp. & Ofloxacin \\
& & Enrofloxacin \\
$\mathbf{3}^{\text {rd }}$ & $2^{\text {nd }}$ group spectrum plus & Gatifloxacin \\
& Streptococcus pneumonia, some & Gemifloxacin \\
& other Gram-positive cocci & Levofloxacin \\
$\mathbf{4}^{\text {th }}$ & $3^{\text {rd }}$ group spectrum plus & Sparfloxacin \\
& Enhanced activity against & Trovafloxacin \\
& anaerobes & Moxifloxacin \\
\end{tabular}

\section{Mechanism of action}

The targets of quinolone action are two large bacterial enzymes; i) DNA gyrase which has two A and two B subunits encoded by the gyrA and gyr B genes, respectively [22]. In addition to, ii) topoisomerase IV which has two pairs of subunits encoded by parC and parE [23]. Both enzymes act together on bacterial DNA synthesis [24], quinolones inhibit the DNA synthesis of the bacteria by acting on both enzymes leading to cell death [25].

\section{Resistance mechanism}

In Gram negative bacteria, the mechanisms causing resistance to fluoroquinolones included target mutations or increased efflux activity $[24,26]$. Also, the target protection by inactivating enzymes mediated by the Plasmid
Mediated Quinolone Resistance (PMQR) mechanisms; the $q n r$ genes, are reported [27]. These genes produce proteins which protect the DNA gyrase or topoisomerase IV enzymes from the inhibitory effect of fluoroquinolones. Additional PMQR mechanisms have been reported, including $a a c\left(6^{\prime}\right)-I b-c r, o q x \mathrm{AB}$ and qерА [26].

In campylobacters, there are two mechanisms that explain resistance to quinolones including inactivation of FQ target and efflux of the drug [28]. The inactivation process is mainly caused by chromosomal mutations in the gyrA gene especially the quinolone resistance determining region (QRDR). However, mutations in gyrB did not confer FQ resistance [29, 30]. Different studies reported that $C$. jejuni and $C$. coli lack the $\operatorname{par} \mathrm{C}$ and parE genes [31]; thus, they cannot be a source of FQ resistance [32, 33]. In 
addition, the PMQR determinants, such as $q n r$, $a a c\left(6^{\prime}\right)-I b-c r$ and qepA, were not documented in campylobacters [26].

Several specific point mutations in gyrA are correlated to quinolone resistance in Campylobacter species: Thr-86-Ile, Asp-90Asn, Thr-86-Lys, Thr-86-Ala, Thr-86-Val, Ala-70-Thr and Asp-90-Tyr. The most common point mutation; Thr-86-Ile; leads to increased resistance to nalidixic acid and ciprofloxacin [34]. While, the less common Asp-90-Asn and Ala-70-Thr mutations confer intermediate resistance [35]. However, the less common Thr-86-Ala mutation confers resistance to nalidixic acid only [36]. Moreover, the following double mutations have been reported to be connected with fluoroquinolone resistance: Thr-86-Ile with Pro-104-Ser and Thr-86-Ile with Asp-90-Asn [33].

Another mechanism of fluoroquinolones resistance efflux; it was reported in 1995 [37, 38]. Efflux pumps are protein complexes located in the bacterial cell membrane and they expel antimicrobials and toxins, lowering their concentration inside the bacterial cell to sub-toxic levels. Thus, giving them the time needed to acquire resistance through more specific adaptive mechanisms [39-41]. These proteins recognize and remove a wide range of antimicrobials of different mechanisms and sites of action. These pumps are also important for bacterial pathogenesis, virulence and biofilm formation [42-44].

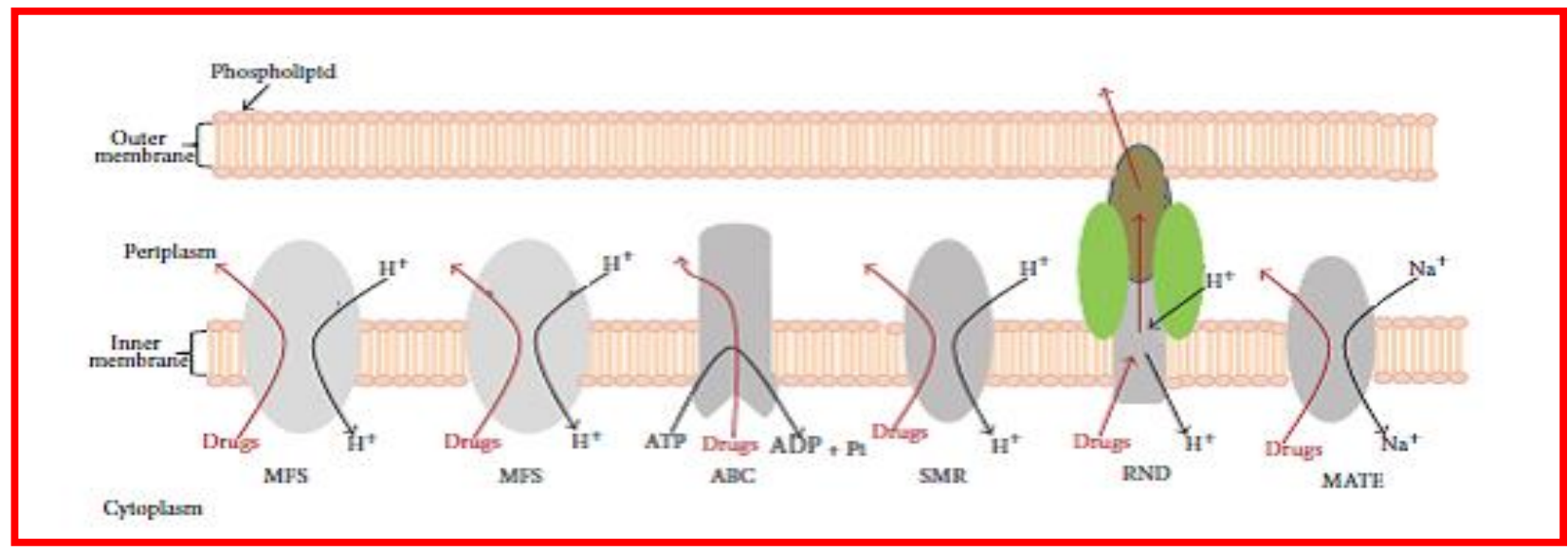

Figure 1: Different types of efflux pumps [45]

Bacterial efflux pumps (Figure 1) belong to five super families [45], namely; (i) ATP Binding Cassette $(\mathrm{ABC})$, which are primary active transporters which depend on ATP hydrolysis and play a major role in drug resistance in eukaryotic cells [46] and are lesser known in bacteria; in $S$. pneumoniae [47] and S. aureus [48]. (ii) Small Multidrug Resistance (SMR) subfamily of the Drug/ Metabolite Transporters (DMT) superfamily. (iii) Multi Antimicrobial Extrusion (MATE) subfamily of the MOP Multidrug/ Oligosaccaridyllipid / Polysaccharide flippases (MOP) superfamily. (iv) Major Facilitator Superfamily (MFS). (v) Resistance / Nodulation/ Divison (RND) superfamily, which are all secondary active transporters driven by ion gradients.

The most abundant pumps are MFS and RND, in Gram negative and Gram-positive bacteria, MFS are characterized by a narrow spectrum (recognizing usually one or few antibiotic classes) [45]. However, RND are found in Gram negative bacteria and have a wide spectrum for several antibiotic classes, antiseptics, dyes and detergents [45].

Genomic sequence of $C$. jejuni revealed 14 putative drug efflux transporters of different families [49]. These membrane transport proteins belong to four families of efflux pumps; DMT, MATE, MFS, and RND [50]. The RND superfamily relies on tripartite protein assemblies that remove antimicrobial agents from the cell through a double membrane. The tripartite protein complex is formed from an inner membrane protein (IMP) [51], an outer membrane protein (OMP), and a periplasmic membrane fusion protein (MFP) which connect IMP and OMP [52] (Figure 2). 


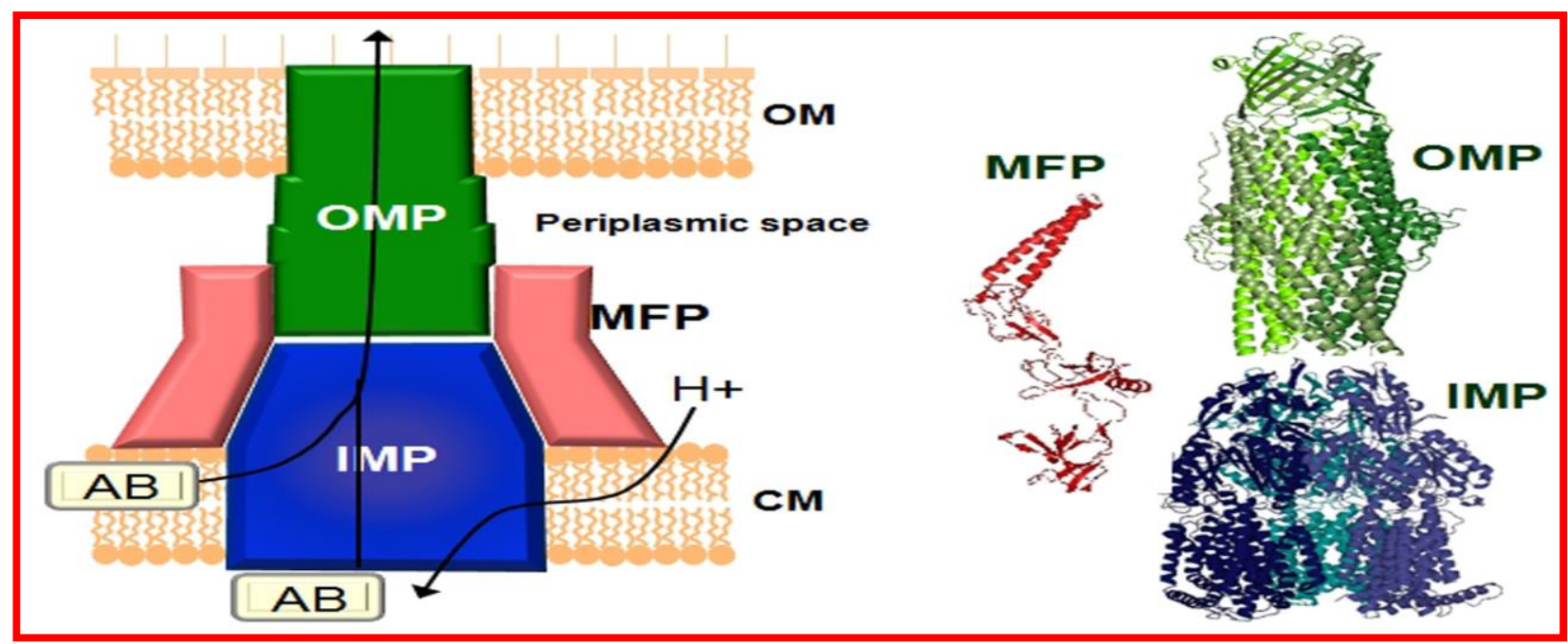

Figure 2: Structure of Resistance/Nodulation/Divison (RND) superfamily [52]

The RND efflux system; cmeABC, was identified and characterized in $C$. jejuni in 2002 [37] and later in C. coli [53]. The cme $\mathrm{ABC}$ efflux system is encoded by three gene operons including $c m e \mathrm{~A}, c m e \mathrm{~B}$, and $c m e \mathrm{C}$. The cmeA is a membrane fusion protein, and its amino acid sequence shows similarity to the membrane fusion component in other bacterial efflux systems in Neisseria gonorrhoeae, Pseudomonas aeruginosa and $E$. coli. The cmeB is an inner membrane transporter and exhibits sequence homology to those of E. coli, P. aeruginosa and Salmonella Typhi. While, cmeC is an outer membrane protein and is similar to those of $P$. aeruginosa and E. coli. CmeABC has established a key role in antibiotic resistance and they function synergistically with other mechanisms in conferring high level resistance to antibiotics [28, 37, 54]. Also, it is essential for pathophysiology of campylobacters [55].

The expression of cmeABC is modulated by two transcriptional regulators named $c m e \mathrm{R}$ and $\cos \mathrm{R}$. The cme R encodes 210-amino acid protein and is located immediately upstream of the cmeABC operon [56]. Homology of the Nterminal sequence of cme R with the members of transcriptional repressors of $S$. aureus, $E$. coli and $N$. gonorrhoeae was reported. The operator site for cmeR binding is a $16 \mathrm{bp}$ inverted repeat (IR) sequence, located between cmeR and cmeA operon. The cme R acts as a repressor for cmeABC, mutations in cme R or its binding site leads to overexpression of cme $\mathrm{ABC}$ and enhances resistance to several classes of antibiotics [55, 57]. The cmeR modulates the expression of additional genes in $C$. jejuni [58], particularly, it controls the expression of Cj0561c (a periplasmic fusion protein) and $\mathrm{Cj} 0035 \mathrm{c}$ (a major facilitator superfamily [MFS] transporter) [59]. Therefore, cme R controls the expression of two types of efflux pumps; RND and MFS superfamily in campylobacters. Recently, certain substrates such as bile salts and salicylate have been reported to interact with cme $\mathrm{R}$ and induce the expression of the cme $\mathrm{ABC}$ efflux system, therefore, it is called efflux inducers $[60,61]$. The second transcriptional regulator for $c m e \mathrm{ABC}$ is $\cos \mathrm{R}$, which is the key regulator for oxidative stress response in campylobacters [62]. The cosR binds to a site which is 17 bp upstream of the cme $\mathrm{R}$ binding site in the promoter region of cme $\mathrm{ABC}$ and represses the expression of this efflux operon [62]. In addition, $\cos \mathrm{R}$ is predicted to be a response regulator of a twocomponent regulatory system, and its inhibition led to overexpression of cmeABC [62]. These findings suggest that oxidative stress response and the antibiotic efflux system are interactive in $C$. jejuni, and $\cos \mathrm{R}$ plays a bridging role in the interaction [54].

Another RND-type efflux pump identified in $C$. jejuni is $c m e \mathrm{DEF}$, the $c m e \mathrm{D}$ is an outer membrane protein that shares low, but significant sequence homology with those in H. pylori and E. coli [55]. The cme $\mathrm{E}$ is a membrane fusion protein that shares significant homology with the membrane fusion protein in $H$. pylori. While, the cme $\mathrm{F}$ is 
an inner membrane transporter which shares homology with other RND-type efflux transporters in H. pylori and E. coli [55]. The cme DEF plays a moderate role in antibiotic resistance in a strain dependent manner and its function is normally masked by that of cmeABC. The regulatory mechanism for cme DEF is not known and the conditions that may induce the expression of $c m e \mathrm{DEF}$ have not been determined. The transcriptional repressor for cmeABC, cme R, does not modulate the expression of $c m e \mathrm{DEF}$ [55].

There are four putative MFS transporters identified in campylobacters; $C j 0035 \mathrm{c}$, Cj1257c, Cj1375 (cmeG), and Cj1687. The cme $\mathrm{G}$ is the only functionally characterized MFS transporter in campylobacters [54, 63], and is present in all strains of $C$. jejuni sequenced to date [63]. It plays a role in the intrinsic resistance to different antibiotics in campylobacters [54, 63]. Analysis of amino acid sequence revealed that cmeG shows homology with the same transporters in $B$. subtilis and $S$. aureus. Inactivation of cmeG significantly decreased the resistance to several classes of antimicrobials including ciprofloxacin, gentamicin, tetracycline, erythromycin, ethidium bromide, and cholic acid, while, overexpression of $c m e \mathrm{G}$ enhanced the resistance to various fluoroquinolones, including ciprofloxacin, enrofloxacin, norfloxacin, and moxifloxacin.

The same features of $c m e G$ are shared with those of MFS efflux pumps in other bacteria which suggest that cmeG may act as a multidrug efflux pump in campylobacters, and also plays an important role in campylobacter resistance to oxidative stress [63]. The expression of cmeG appears to be regulated by Fur protein and iron concentrations for inactivation of Fur or depleting iron resulted in up-regulated expression of cmeG [64, 65]. The transcription of cmeG occurred together with its downstream gene $c m e \mathrm{H}$, which is not present in all $C$. jejuni strains. The $\mathrm{cmeH}$ encodes a putative periplasmic protein with has sequence similarity to $B$. subtilis yuiI and Salmonella enterica iroE [49]. These proteins are associated with siderophore uptake in these bacteria [66]. The mutations in $\mathrm{cmeH}$ not affect its resistance to antimicrobial agents, suggesting that $\mathrm{cmeH}$ alone does not have a role in antimicrobial resistance. Meanwhile, fluoroquinolones resistance was significantly increased in $C$. jejuni with overexpressed cme $\mathrm{GH}$ operon. In addition, ciprofloxacin was more accumulated in strains with mutant cmeG than the wild type strain [63].

Fluoroquinolones cause bacterial death by forming a stable complex with gyrases and DNA [22]. However, antibiotic treatments induce the SOS response in some bacteria. This response upregulates many genes involved in DNA repair, recombination and mutation. These genes are also involved in other functions such as drug resistance development, virulence factors production and horizontal transfer of genetic materials [67, 68]. Han [69], in the presence and absence of ciprofloxacin, compared the different gene expression profiles of $C$. jejuni using DNA microarray. The results showed that multiple genes were significantly changed in their expression in the presence of ciprofloxacin with subtherapeutic concentrations. The $m f d$ (mutation frequency decline) gene was one of these up-regulated genes, which is involved in DNA repair [70, 71]. Mutation of this gene resulted in reduction in the spontaneous mutation rate to ciprofloxacin resistance with 100 fold approximately, while, $m f d$ gene overexpression elevated the mutation frequency [69]. In addition, the development of fluoroquinolone resistant $C$. jejuni in culture media or chickens treated with fluoroquinolones was significantly reduced by lossing $m f d$ gene. Thus, indicating the impotant role of $m f d$ in the development of quinolone resistance in campylobacters [69]. Campylobacters may not have the typical SOS response system and the error-prone DNA polymerases [69]. Thus, $m f d$ as an alternative pathway for increasing mutation rates may be used by $C$. jejuni when imposed by $\mathrm{FQ}$ treatment [69].

\section{Macrolides}

\section{Classification}

The macrolides are group of antibiotics that inhibit protein synthesis. Erythromycin is the first natural macrolide discovered at 1952 in Streptomyces erythreus. This class includes also azithromycin, clarithromycin, telithromycin (ketolide) and two veterinary drugs namely, tylosin and tilmicosin. All 
macrolide compounds share a lactone ring, and according to this ring structure, they can be divided into either 14-, 15-, or 16-membered compounds [72].

\section{Mechanism of action}

Macrolides bind reversibly to bacterial ribosomes at the $\mathrm{P}$ site on the 50s subunit leading to inhibition of bacterial protein synthesis [73]. The key nucleotides contact sites at which macrolide binds mainly are Ala 2058 and Ala 2059 at which macrolides bind and terminate the elongation of the synthetizing peptide chain [74].

\section{Resistance mechanism}

Four macrolide resistance mechanisms were identified; including; target sites modification by mutation or methylation, antibiotic inactivation, active antibiotic efflux and altered membrane permeability [75]. There are three copies of 23S rRNA gene in $C$. jejuni and $C$. coli. In macrolide resistant strains, three copies are usually mutated (homozygous mutation) [49]. Mutations at the positions 2074 or 2075 of the $23 \mathrm{~S}$ rRNA gene cause high level of resistance to macrolides with the 2075 substitution being more common [76, 77]. However, some strains with low macrolides resistance were found to have mutation in one gene copy (heterozygous mutation), suggesting a dose effect of the gene [78]. However, there are no reports of macrolide-resistant campylobacter strains containing only one mutated copy of the $23 \mathrm{~S}$ rRNA gene $[76,79]$. In addition, the resistance may be caused by posttranslational modifications of the ribosomal proteins $\mathrm{L}_{4}$ and $\mathrm{L}_{22}$ [80-82].

Erythromycin is an antibiotic synthesized by the Gram-positive bacterium Streptomyces erythreus, which protects its own ribosomes by expression of a methyltransferase; ermE, that specifically modifies nucleotide A2058 within 23S rRNA [83].

Enzyme-mediated methylation ( $\mathrm{erm})$ genes, can cause macrolide resistance, however, it has been only reported in Campylobacter rectus [84]. Recently, Qin [75] identified the first horizontally transferrable macrolide resistance mechanism in $C$. coli isolated from porcine. This resistance mechanism is mediated by a ribosomal RNA methylase, $\operatorname{erm}(\mathrm{B})$, which is
$738 \mathrm{bp}$ in length and has $100 \%$ similarity to the erm $\mathrm{B}$ genes identified in Streptococcus suis, Enterococcus faecium and Lactobacillus plantarum plasmid pLFE1, in which, this gene alone was responsible for the high level of macrolide resistance [75].

The third mechanism of macrolide resistance is the alteration of membrane permeability which is mediated by expression of the major outer membrane porin (MOMP) and chromosomally encoded by porA [85]. The outer membrane porins in campylobacters are cation selective pores and smaller than typical pores found in E. coli. The smaller pores in campylobacters limit the entry of most antibiotics with a molecular weight greater than 360 Kilo Dalton [86]. Although, macrolides are large molecules (MW > 700 kda) [85, 87], they are very effective against campylobacters. Thus, suggesting that macrolides are able to cross the outer and cytoplasmic membranes. The porins may provide an aqueous environment for transportation of the relatively hydrophobic macrolides and thought to provide access for macrolides to cytoplasm via a "hydrophobic pathway" in Gram-negative bacteria [88]. The outer membrane of campylobacters is naturally lipooligosaccharide (LOS) not lipopolysaccharide (LPS) as in other Gramnegative bacteria, due to lack of the hydrophilic sugars. The LOS membrane in campylobacters increases the hydrophobicity effect and promotes macrolides uptake [89]. This theory is supported by the observation that LOS truncation in $C$. jejuni strains decreases the resistance to erythromycin by 8 folds and that effect was doubled in strains with A2074G mutation [90].

The third mechanism of macrolide resistance is the efflux system which causes macrolide resistance [78], and works in synergism with other mechanisms of resistance providing a high level of resistance [81].

\section{Targeting efflux mechanisms to control Campylobacter resistance}

The membrane transporter proteins overexpression is widely known as Multidrug Efflux Systems (MES), which are found in clinical isolates with levels of resistance to antibiotics. Thus, the multidrug transporters 
may be the major determinant in the efficacy for antibiotics [91]. Continuous efforts are made to find substances capable of controlling the action of efflux pumps and reversing antimicrobial resistance in vivo [92]. The substances used for evaluation of efflux pumps activities were either efflux pump inhibitors (EPIs) or efflux pump inducers. The similarity in different Gram-negative transporters structure means that efflux pump inhibitors developed against $E$. coli could be effective against other Gram-negative pathogens [52]. There are at least two classes of broad spectrum efflux pump inhibitors; peptidomimetics and pyridopyrimidines, have been reported [91].

The peptidomimetics family shows EPI properties. The phenylalanine arginyl $\beta$ naphthylamide $(\mathrm{Pa} \beta \mathrm{N})$ is the first identified EPI in this group and is capable of reversing resistance in various $P$. aeruginosa clinical strains against levofloxacin, chloramphenicol and macrolides [93, 94]. It has an activity against a variety of Gram negative bacteria, such as $E$. coli, $S$. Typhimurium, $K$. pneumonia [95] and campylobacters [76, 96, 97]. The inhibition mechanism of $P A \beta N$ was reported to be effective against RND substrate [95], and it significantly decreases the ciprofloxacin resistance in $C$. jejuni and C. coli (2-512 fold reductions) [98].

Verapamil and phenothiazines; $\mathrm{Ca}^{2+}$ channel blockers, inhibit efflux pump activity of both MFS and ABC substrates by reducing the transmembrane proton-motive force (PMF) potential [99]. They are used as an inhibitor of MDR pumps of cancer cells and also improve the tobramycin activity [100]. They are FDA approved EPI and provide a promising effect as adjunctive chemotherapy for treatment of tuberculosis by inhibiting MFS efflux pump $[101,102]$ restoring susceptibility to ofloxacin in Mycobacterium tuberculosis and M. avium strains [103, 104]. The main side effects of using verapamil are neurotoxicity [100] and hypotension [105].

Phenothiazines such as chlorpromazine and promethazine are tricyclic neuroleptics [106]. Chlorpromazine inhibits the PMF-dependent MFS pumps [107, 108] in M. tuberculosis, $M$. smegmatis and M. avium complex [109, 110], Burkholderia cepacia [111], staphylococci, E. coli [112], Burkholderia pseudomallei [113] and Salmonella enterica strains [114]. Chlorpromazine significantly decreases the resistance of wide spectrum of antimicrobial agents including levofloxacin, leading to a significant reduction in MIC values [113]. Also, it has been shown to reverse MDR phenotype of MRSA (methicillin-resistant $S$. aureus) strains, $S$. Typhimurium, and $P$. aeruginosa. These drugs may inhibit the PMF dependent pumps. This action may be obtained by reduction in trans-membrane potential or by their direct interaction with the pump [115, 116]. Therefore, its inhibition mechanism was proposed to be acting on MFS and $\mathrm{ABC}$ substrates [114, 117-120].

Alpha-tocopherol is an isoform of vitamin $\mathrm{E}$ and characterizes by a lipophilic character which permits the perturbations in cell membrane, leading to damage of the membrane integrity and followed by the collapse of pumps [121, 122]. In vitro, it showed a modulatory effect in Gram-negative strains mainly with high level of aminoglycosides resistance. That effect may be due to composition of Gram-negative bacteria which are characterized by higher amount of lipids than Gram-positive bacteria. Therefore, the greater effect of alphatocopherol [123-125] is modulating E. coli and $P$. aeruginosa more effectively, when compared with $S$. aureus [126]. It represents a new approach against microbial resistance [126].

Different types of inducers such as salicylate and bile salts can be used. The principal metabolites of aspirin (acetylsalicylic acid) are salicylic acid and salicylate [127], and it is a nonsteroidal anti-inflammatory drug (NSAID) widely used in livestock animals and poultry [128]. It suppresses the normal functioning of platelets. Aspirin is naturally stable in dry atmosphere, but when contact with moisture it is hydrolysed to salicylic acids and acetic acid [129]. Also, the salicylic acid is widely distributed in foods, plants and beverages $[130,131]$. Thus, salicylate can reach humans and food producing animals through different sources. Regarding the great effect of salicylate on mammalian cells, it affects the susceptibility of bacteria to different groups of antibiotics. 
That effect occurs due to growth of bacteria in the presence of salicylate around, inducing non-heritable resistance to various groups of antibiotics [132]. Moreover, the resistance pattern of campylobacters is increased to antibiotics in presence of salicylate [61]. Salicylate decreases antibiotics susceptibility by two different mechanisms of actions. Firstly, it may induce over expression of cme $\mathrm{ABC}$ by binding to $\mathrm{cme} \mathrm{R}$ and inhibiting its action to cmeABC leading to an increase in resistance to antibiotics especially ciprofloxacin and thus increasing emergence of fluoroquinolone resistant mutation [61]. Secondary, it alters membrane proteins, induces efflux pumps and decreases the susceptibility of certain bacteria such as E. coli [132]. C. jejuni has an outer-membrane porin (MOMP) [133] and multidrug efflux pump (cmeABC) belonging to the same families in E. coli [37]. This may suggest that salicylate could decrease the susceptibility of antibiotics by decreasing antibiotic accumulation in campylobacter cells. Previous studies; Randall [134] and Hannula and Hänninen [92] reported that salicylate induced a significant increase in resistance to ciprofloxacin and erythromycin in most of the examined campylobacter strains.

Table 2: Resistance pattern of macrolides in campylobacters, especially $C$. jejuni and $C$. coli, in chickens and humans in several Governorates in Egypt

\begin{tabular}{|c|c|c|c|c|c|}
\hline Year & Area & Samples & Species & $\begin{array}{c}\text { ERY } \\
\text { Resistance\% }\end{array}$ & Ref \\
\hline 1995 & Cairo & Human & C. jejuni & $\hat{0}$ & $\begin{array}{l}13777 \\
{[137]}\end{array}$ \\
\hline 1995 & Cairo & Human & C. coli & 0 & [137] \\
\hline 1996 & Cairo & Human & Campylobacter spp. & 0 & [137] \\
\hline 1996 & Cairo & Human & C. jejuni & 0 & [137] \\
\hline 1996 & Cairo & Human & C. coli & 0 & [137] \\
\hline 1997 & Cairo & Human & Campylobacter spp. & 0 & [137] \\
\hline 1997 & Cairo & Human & C. jejuni & 0 & [137] \\
\hline 1997 & Cairo & Human & C. coli & 0 & [137] \\
\hline 1998 & Cairo & Human & Campylobacter spp. & 0 & [137] \\
\hline 1998 & Cairo & Human & C. jejuni & 0 & [137] \\
\hline 1998 & Cairo & Human & C. coli & 0 & [137] \\
\hline 1999 & Cairo & Human & Campylobacter spp. & 0 & [137] \\
\hline 1999 & Cairo & Human & C. jejuni & 0 & [137] \\
\hline 1999 & Cairo & Human & C. coli & 0 & [137] \\
\hline 2000 & Cairo & Human & Campylobacter spp. & 0 & [137] \\
\hline 2000 & Cairo & Human & C. jejuni & 0 & [137] \\
\hline 2000 & Cairo & Human & C. coli & 0 & [137] \\
\hline 2000 & Cairo & Human & C. jejuni & 9 & [138] \\
\hline 2000 & Cairo & Human & C. coli & 10 & [138] \\
\hline 2006 & Fayoum & Children & Campylobacter spp. & 0 & [139] \\
\hline 2006 & Mansoura & Children & C. jejuni \& C. coli & 42.8 & [4] \\
\hline 2011 & Giza & Chicken & C. jejuni & 58.82 & [147] \\
\hline 2011 & Giza & human & C. jejuni & 62.5 & [147] \\
\hline 2014 & Cairo & human & C. jejuni \& C. coli & 94.7 & [142] \\
\hline 2014 & Zagazig & human & C. jejuni \& C. coli & 100 & [143] \\
\hline 2014 & Zagazig & Chicken & C. jejuni \& C. coli & 100 & [143] \\
\hline 2014 & Zagazig & Chicken, human & C. jejuni & 83.3 & [144] \\
\hline 2014 & Cairo, Giza, Kaliobia, Monefia, Fayoum & Chicken, human & C. jejuni & 76.2 & [145] \\
\hline 2014 & Cairo, Giza, Kaliobia, Monefia, Fayoum & Chicken & C. jejuni & 80 & [145] \\
\hline 2014 & Cairo, Giza, Kaliobia, Monefia, Fayoum & Human & C. jejuni & 50 & [145] \\
\hline 2014 & Cairo, Giza, Kaliobia, Monefia, Fayoum & Chicken & C. coli & 100 & [145] \\
\hline 2014 & Cairo, Giza, Kaliobia, Monefia, Fayoum & Human & C. coli & 100 & [145] \\
\hline 2014 & Cairo, Giza, Kaliobia, Monefia, Fayoum & Chicken & C. coli & 100 & [145] \\
\hline 2014 & Cairo, Giza, Kaliobia, Monefia, Fayoum & Human & C. coli & 100 & [145] \\
\hline 2014 & Zagazig & human & C. coli & 100 & [144] \\
\hline 2014 & Zagazig & Chicken & C. coli & 100 & [144] \\
\hline
\end{tabular}




\section{Incidence of resistance in Egypt}

Although campylobacteriosis is endemic in Egypt and considered a major cause for pediatric diarrhea [135], fluoroquinolone and macrolide resistance, was recently documented to increase in the isolated strains in Egypt [136-147]. In the period from 1991 to 2016, several studies screened and analyzed the resistance pattern of macrolides and FQ in campylobacters, especially $C$. jejuni and $C$. coli, in chickens and humans in several Governorates in Egypt as shown in Tables 2 and 3 [136-147]. Putnam [137] analyzed the annual prevalence of macrolides resistance rate in Cairo from 1995 till 2000, which was $0 \%$. The first low level of resistance to macrolides $(10 \%$ in $C$. coli and $9 \%$ in $C$. jejuni) was recorded in Cairo by Wasfy [138]. However, Putnam [137] did not record this resistance in the same Governorate. In 2006, marked increase in resistance level of macrolides was obviously observed in Mansoura Governorate $(42.8 \%)$ by Omar [140], While, no resistance was reported in Fayoum Governorate [139]. Recently, different studies reported higher resistance rates of $C$. jejuni and $C$. coli in samples obtained from chickens and humans, $94.7 \%$ in Cairo [142], 83.3\% in Zagazig [144] and $100 \%$ in Cairo, Giza, Kaliobia, Monefia, Fayoum and Zagazig [143, 145].

Table 3: Resistance pattern of fluoroquinolones in campylobacters, especially $C$. jejuni and $C$. coli, in chickens and humans in several Governorates in Egypt (CIP: ciprofloxacin, NA: nalidixic acid)

\begin{tabular}{|c|c|c|c|c|c|c|}
\hline Year & Area & Samples & Species & CIP & NA & Ref \\
\hline 1991 & Alex & Human & Campylobacter spp. & & 0 & [136] \\
\hline 1995 & Cairo & Human & Campylobacter spp. & 12.9 & & [137] \\
\hline 1995 & Cairo & Human & C. jejuni & 16.7 & & [137] \\
\hline 1995 & Cairo & Human & C. coli & 0 & & [137] \\
\hline 1996 & Cairo & Human & Campylobacter spp. & 27.6 & & [137] \\
\hline 1996 & Cairo & Human & C. jejuni & 39.6 & & [137] \\
\hline 1996 & Cairo & Human & C. coli & 8.8 & & [137] \\
\hline 1997 & Cairo & Human & Campylobacter spp. & 35.1 & & [137] \\
\hline 1997 & Cairo & Human & C. jejuni & 44.3 & & [137] \\
\hline 1997 & Cairo & Human & C. coli & 21.2 & & [137] \\
\hline 1998 & Cairo & Human & Campylobacter spp. & 50 & & [137] \\
\hline 1998 & Cairo & Human & C. jejuni & 46.3 & & [137] \\
\hline 1998 & Cairo & Human & C. coli & 29.4 & & [137] \\
\hline 1999 & Cairo & Human & Campylobacter spp. & 48 & & [137] \\
\hline 1999 & Cairo & Human & C. jejuni & 57.7 & & [137] \\
\hline 1999 & Cairo & Human & C. coli & 39.7 & & [137] \\
\hline 2000 & Cairo & Human & Campylobacter spp. & 48.2 & & [137] \\
\hline 2000 & Cairo & Human & C. jejuni & 58.3 & & [137] \\
\hline 2000 & Cairo & Human & C. coli & 32 & & [137] \\
\hline 2000 & Cairo & Human & C. jejuni & & 40 & [138] \\
\hline 2000 & Cairo & Human & C. coli & & 24 & [138] \\
\hline 2006 & Fayoum & Children & Campylobacter spp. & 100 & & [139] \\
\hline 2006 & Mansoura & Children & C. jejuni \& C. coli & 92.8 & 100 & [4] \\
\hline 2014 & Menia & Human & Campylobacter spp. & 20 & & [141] \\
\hline 2014 & Cairo & Human & C. jejuni \& C. coli & 57.9 & 100 & [142] \\
\hline 2014 & Zagazig & Chicken & C. jejuni \& C. coli & 100 & 100 & [143] \\
\hline 2014 & Zagazig & Human & C. jejuni \& C. coli & 100 & 100 & [143] \\
\hline 2014 & Zagazig & Chicken, human & C. jejuni & & 50 & [144] \\
\hline 2014 & Minia & Human & C. jejuni & 20 & & [141] \\
\hline 2014 & Cairo, Giza, Kaliobia, Monefia, Fayoum & Chicken, Human & C. jejuni & 80.9 & 83.3 & [145] \\
\hline 2014 & Cairo, Giza, Kaliobia, Monefia, Fayoum & Chicken & C. jejuni & 81.6 & 84.2 & [145] \\
\hline 2014 & Cairo, Giza, Kaliobia, Monefia, Fayoum & Human & C. jejuni & 75 & 75 & [145] \\
\hline 2014 & Cairo, Giza, Kaliobia, Monefia, Fayoum & Chicken, human & C. coli & 85.7 & 92.9 & [145] \\
\hline 2014 & Cairo, Giza, Kaliobia, Monefia, Fayoum & Chicken & C. coli & 83.3 & 100 & [145] \\
\hline 2014 & Cairo, Giza, Kaliobia, Monefia, Fayoum & Human & C. coli & 100 & 50 & [145] \\
\hline 2014 & Zagazig & Chicken, human & C. coli & & 75 & [144] \\
\hline 2016 & Giza & $1 \mathrm{~d}$ old ducklings & C. jejuni & 66.7 & & [146] \\
\hline 2016 & Giza & $1 \mathrm{~d}$ old ducklings & C. coli & 42 & & [146] \\
\hline
\end{tabular}


Although the resistance rate of FQ was $0 \%$ in 1991 [136], the FQ resistance rates were early observed than macrolides [137]. Putnam [137] analyzed the annual prevalence of FQ resistance from 1995 till 2000 in Cairo. A significant increased linear trend in the rates of resistance for FQ during the study period was observed, which reached $58.3 \%$ in 2000 from $16.7 \%$ in 1995 for C. jejuni. By 2006, different studies reported high FQ resistance rates of $C$. jejuni and $C$. coli in samples obtained from chickens and humans, $100 \%$ in Fayoum, Mansoura, Cairo and Zagazig [139, 140, 142, 143], 83.3\% in Cairo, Giza, Kaliobia, Monefia, Fayoum (for C. jejuni) [145] and $92.9 \%$ in Cairo, Giza, Kaliobia, Monefia, Fayoum (for C. coli) [145]. Thus, the study of the resistance mechanisms in $C$. jejuni and $C$. coli is important for both humans and veterinary health.

\section{Conclusion}

In conclusion, the increase in FQ and macrolides resistance in campylobacters is documented in Egypt. Therefore, continuous and regular survey for resistance to these drugs is essential for control of infections, which in turn has an impact on human health and veterinary sectors.

\section{Conflict of interest}

The authors have no conflict of interest to declare.

\section{References}

[1] EFSA. (2008): The community summary report on trends and sources of zoonoses, zoonotic agents and food-borne outbreaks in the European Union in 2008. EFSA J, 8(1): 1496.

[2] Halablab, M.A., Mohammed, K.A.S. and Miles, R.J. (2008): Growth and survival of Campylobacter pathogens in the presence of different metabolic inhibitors. J Medical Sci, 8(3): 262-8.

[3] Song, Y.C.; Jin, S.; Louie, H.; Ng, D.; Lau, R.; Zhang, Y.; Weerasekera, R.; Al Rashid, S.; Ward, L.A.; Der, S.D. and Chan, V.L. (2004): FlaC, a protein of Campylobacter jejuni TGH9011 (ATCC43431) secreted through the flagellar apparatus, binds epithelial cells and influences cell invasion. Mol Microbiol, 53(2): 541-53.

[4] Koneman, E.W., Allen, S.D., Janda, W.M., Schreckenberger, P.C. and Winn, W.C. (1997): Color Atlas and Textbook of Diagnostic Microbiology 5th edition. 32238.

[5] Blaser and Martin, J. (2000): Campylobacter jejuni and Related Species. Mandell, Douglas, and Bennett's Principles and Practice of Infectious Diseases, 5: Chap. 204, pp. 2276-85.

[6] ISO. (2006): Microbiology of Food and Animal Feeding Stuffs - Horizontal Method for Detection and Enumeration of Campylobacter spp. Part 1: Detection Method. Geneva: International Organization for Standardization [ISO 10272-1:2006].

[7] On, S.L.W. (1996): Identification method for Campylobacters, Helicobacters and related organism. Clin Microdiol Rev, 9(3): 405-22.

[8] Steinhauserova, I.; Ceskova, J.; Fojtikova, K. and Obrovska, I. (2001): Identification of thermophilic Campylobacter spp. by phenotypic and molecular methods. J Appl Microbiol, 90(3): 470-5.

[9] Waino, M.; Bang, D.D.; Lund, M.; Nordentoft, S.; Andersen, J.S.; Pedersen, K. and Madsen, M. (2003): Identification of campylobacteria isolated from Danish broilers by phenotypic tests and speciesspecific PCR assays. J Appl Microbiol, 95(4): 649-55.

[10]Takkinen, J., Ammon, A., Robstad, O. and Breuer, T. . (2002): The Campylobacter Working Group. European Survey on Campylobacter Surveillance and Diagnostics 2000, Campylobacter Infections. . Report to the European Commission, DG SANCO 4, Berlin,: 1107.

[11]Hermans, D.; Van Deun, K.; Martel, A.; Van Immerseel, F.; Messens, W.; Heyndrickx, M.; Haesebrouck, F. and Pasmans, F. (2011): Colonization factors of Campylobacter jejuni in the chicken gut. Vet Res, 42: 82. 
[12]Alba, A.H.A. (1998): A contribution on Campylobacter organisms in birds. $\mathrm{PhD}$ thesis Bacteriology Dep, Fac Vet Med Cairo Univ.

[13] De Zoete, M.R.; van Putten, J.P. and Wagenaar, J.A. (2007): Vaccination of chickens against Campylobacter. Vaccine, 25(30): 5548-57.

[14]Coward, C.; van Diemen, P.M.; Conlan, A.J.; Gog, J.R.; Stevens, M.P.; Jones, M.A. and Maskell, D.J. (2008): Competing isogenic Campylobacter strains exhibit variable population structures in vivo. Appl Environ Microbiol, 74(12): 3857-67.

[15] Moore, J.E.; Corcoran, D.; Dooley, J.S.; Fanning, S.; Lucey, B.; Matsuda, M.; McDowell, D.A.; Megraud, F.; Millar, B.C.; O'Mahony, R.; O'Riordan, L.; O'Rourke, M.; Rao, J.R.; Rooney, P.J.; Sails, A. and Whyte, P. (2005): Campylobacter. Vet Res, 36(3): 351-82.

[16] Nachamkin, I.; Szymanski, C.M. and Blaser, M.J. Campylobacter: ASM Press; 2008.

[17]Boyanova, L.; Gergova, G.; Spassova, Z.; Koumanova, R.; Yaneva, P.; Mitov, I.; Derejian, S. and Krastev, Z. (2004): Campylobacter infection in 682 Bulgarian patients with acute enterocolitis, inflammatory bowel disease, and other chronic intestinal diseases. Diagnostic Microbiol and Infect Dis, 49(1): 71-4.

[18]Rao, D.; Rao, J.; Crothers, E.; McMullan, R.; McDowell, D.; McMahon, A.; Rooney, P.; Millar, B.C. and Moore, J. (2005): Increased erythromycin resistance in clinical Campylobacter in Northern Ireland-an update. J Antimicrob Chemother, 55(3): 395-6.

[19]Luangtongkum, T.; Jeon, B.; Han, J.; Plummer, P.; Logue, C.M. and Zhang, Q. (2009): Antibiotic resistance in Campylobacter: emergence, transmission and persistence. Future Microbiol, 4(2): 189-200.

[20]Gibreel, A.; Tracz, D.M.; Nonaka, L.; Ngo, T.M.; Connell, S.R. and Taylor, D.E. (2004): Incidence of antibiotic resistance in Campylobacter jejuni isolated in Alberta, Canada, from 1999 to 2002, with special reference to tet (O)-mediated tetracycline resistance. Antimicrob Agents Chemother, 48(9): 3442-50.

[21]Van Bambeke, F.; Michot, J.M.; Van Eldere, J. and Tulkens, P. (2005): Quinolones in 2005: an update. Clin Microbiol Infect, 11(4): 256-80.

[22]Drlica, K. and Zhao, X. (1997): DNA gyrase, topoisomerase IV, and the 4quinolones. Microbiol Mol Biol Rev, 61(3): 377-92.

[23]Kato, J.-i.; Nishimura, Y.; Imamura, R.; Niki, H.; Hiraga, S. and Suzuki, H. (1990): New topoisomerase essential for chromosome segregation in E. coli. Cell, 63(2): 393-404.

[24]Jacoby, G.A. (2005): Mechanisms of resistance to quinolones. Clin Infect Dis, 41(Supplement 2): S120-S6.

[25]Maxwell, A. (1992): The molecular basis of quinolone action. $\mathrm{J}$ Antimicrob Chemother, 30(4): 409-14.

[26]Strahilevitz, J.; Jacoby, G.A.; Hooper, D.C. and Robicsek, A. (2009): Plasmidmediated quinolone resistance: a multifaceted threat. Clin Microbiol Rev, 22(4): 664-89.

[27]Martínez-Martínez, L.; Pascual, A. and Jacoby, G.A. (1998): Quinolone resistance from a transferable plasmid. The Lancet, 351(9105): 797-9.

[28]Yan, M.; Sahin, O.; Lin, J. and Zhang, Q. (2006): Role of the CmeABC efflux pump in the emergence of fluoroquinoloneresistant Campylobacter under selection pressure. J Antimicrob Chemother, 58(6): 1154-9.

[29]Payot, S.; Cloeckaert, A. and ChaslusDancla, E. (2002): Selection and characterization of fluoroquinoloneresistant mutants of Campylobacter jejuni using enrofloxacin. Microb Drug Resist, 8(4): 335-43.

[30]Piddock, L.J.; Ricci, V.; Pumbwe, L.; Everett, M.J. and Griggs, D.J. (2003): Fluoroquinolone resistance in Campylobacter species from man and animals: detection of mutations in 
topoisomerase genes. J Antimicrob Chemother, 51(1): 19-26.

[31]Cooper, R.; Segal, H.; Lastovica, A. and Elisha, B. (2002): Genetic basis of quinolone resistance and epidemiology of resistant and susceptible isolates of porcine Campylobacter coli strains. J Appl Microbiol, 93(2): 241-9.

[32]Bachoual, R.; Dubreuil, L.; Soussy, C.-J. and Tankovic, J. (2000): Roles of gyrA mutations in resistance of clinical isolates and in vitro mutants of Bacteroides fragilis to the new fluoroquinolone trovafloxacin. Antimicrob Agents Chemother, 44(7): 1842-5.

[33]Payot, S.; Bolla, J.-M.; Corcoran, D.; Fanning, S.; Mégraud, F. and Zhang, Q. (2006): Mechanisms of fluoroquinolone and macrolide resistance in Campylobacter spp. Microbes Infect, 8(7): 1967-71.

[34]Gootz, T.D. and Martin, B.A. (1991): Characterization of high-level quinolone resistance in Campylobacter jejuni. Antimicrob Agents Chemother, 35(5): 840-5.

[35]Ruiz, J.; Goñi, P.; Marco, F.; Gallardo, F.; Mirelis, B.; Anta, T.J.D. and Vila, J. (1998): Increased resistance to quinolones in Campylobacter jejuni: a genetic analysis of gyrA gene mutations in quinoloneresistant clinical isolates. Microbiol Immunol, 42(3): 223-6.

[36]Jesse, T.; Englen, M.; Pittenger-Alley, L. and Fedorka-Cray, P. (2006): Two distinct mutations in gyrA lead to ciprofloxacin and nalidixic acid resistance in Campylobacter coli and Campylobacter jejuni isolated from chickens and beef cattle. J Appl Microbiol, 100(4): 682-8.

[37]Lin, J.; Michel, L.O. and Zhang, Q. (2002): CmeABC functions as a multidrug efflux system in Campylobacter jejuni. Antimicrob Agents Chemother, 46(7): 2124-31.

[38]Charvalos, E.; Tselentis, Y.; Hamzehpour, M.M.; Köhler, T. and Pechere, J.-C. (1995): Evidence for an efflux pump in multidrug-resistant Campylobacter jejuni. Antimicrob Agents Chemother, 39(9): 2019-22.
[39]Nikaido, H. and Pagès, J.-M. (2012): Broad-specificity efflux pumps and their role in multidrug resistance of Gramnegative bacteria. FEMS Microbiol Rev, 36(2): 340-63.

[40]Piddock, L.J. (2006): Clinically relevant chromosomally encoded multidrug resistance efflux pumps in bacteria. Clin Microbiol Rev, 19(2): 382-402.

[41]Poole, K. (2004): Efflux-mediated multiresistance in Gram-negative bacteria. Clin Microbiol Infect, 10(1): 12-26.

[42]Amaral, L.; Martins, A.; Spengler, G. and Molnar, J. (2014): Efflux pumps of Gramnegative bacteria: what they do, how they do it, with what and how to deal with them. Front Pharmacol, 4: 168.

[43]Baugh, S.; Ekanayaka, A.S.; Piddock, L.J. and Webber, M.A. (2012): Loss of or inhibition of all multidrug resistance efflux pumps of Salmonella enterica serovar Typhimurium results in impaired ability to form a biofilm. $\mathrm{J}$ Antimicrob Chemother, 67(10): 2409-17.

[44]Martinez, J.L.; Sánchez, M.B.; MartínezSolano, L.; Hernandez, A.; Garmendia, L.; Fajardo, A. and Alvarez-Ortega, C. (2009): Functional role of bacterial multidrug efflux pumps in microbial natural ecosystems. FEMS microbiology reviews, 33(2): 430-49.

[45]Kumar, S.; Mukherjee, M.M. and Varela, M.F. (2013): Modulation of bacterial multidrug resistance efflux pumps of the major facilitator superfamily. Int $\mathbf{J}$ Bacteriol, 2013.

[46]Van Bambeke, F.; Michot, J.-M. and Tulkens, P. (2003): Antibiotic efflux pumps in eukaryotic cells: occurrence and impact on antibiotic cellular pharmacokinetics, pharmacodynamics and toxicodynamics. J Antimicrob Chemother, 51(5): 1067-77.

[47]Marrer, E.; Schad, K.; Satoh, A.T.; Page, M.G.; Johnson, M.M. and Piddock, L.J. (2006): Involvement of the putative ATPdependent efflux proteins PatA and PatB in fluoroquinolone resistance of a multidrug-resistant mutant of 
Streptococcus pneumoniae. Antimicrob Agents Chemother, 50(2): 685-93.

[48]Kadlec, K. and Schwarz, S. (2009): Novel $\mathrm{ABC}$ transporter gene, vga $(\mathrm{C})$, located on a multiresistance plasmid from a porcine methicillin-resistant Staphylococcus aureus ST398 strain. Antimicrob Agents Chemother, 53(8): 3589-91.

[49]Parkhill, J.; Wren, B.; Mungall, K.; Ketley, J.; Churcher, C.; Basham, D.; Chillingworth, T.; Davies, R.; Feltwell, T. and Holroyd, S. (2000): The genome sequence of the food-borne pathogen Campylobacter jejuni reveals hypervariable sequences. Nature, 403(6770): 665-8.

[50]Ge, B.; McDermott, P.F.; White, D.G. and Meng, J. (2005): Role of efflux pumps and topoisomerase mutations in fluoroquinolone resistance in Campylobacter jejuni and Campylobacter coli. Antimicrob Agents Chemother, 49(8): 3347-54.

[51]Rodgers, J.; Simpkin, E.; Lee, R.; Clifton-Hadley, F. and Vidal, A. (2016): Sensitivity of Direct Culture, Enrichment and PCR for Detection of Campylobacter jejuni and $C$. coli in Broiler Flocks at Slaughter. Zoonoses and public health, 64(4), 262-271.

[52]Venter, H.; Mowla, R.; Ohene-Agyei, T. and Ma, S. (2015): RND-type drug efflux pumps from Gram-negative bacteria: molecular mechanism and inhibition. Front Microbiol, 6: 377.

[53]Corcoran, D.; Quinn, T.; Cotter, L.; O'Halloran, F. and Fanning, S. (2005): Characterization of a cme $\mathrm{ABC}$ operon in a quinolone-resistant Campylobacter coli isolate of Irish origin. Microbial Drug Resistance, 11(4): 303-8.

[54]Li, X.-Z.; Elkins, C.A. and Zgurskaya, H.I. (2016): Efflux-Mediated Antimicrobial Resistance in Bacteria. Springer International Publishing, 359400.

[55]Lin, J.; Akiba, M. and Zhang, Q. (2005): Multidrug Efflux Systems in Campylobacter. Campylobacter: Molecular and Cellular Biology book, 205.
[56]Lin, J.; Akiba, M.; Sahin, O. and Zhang, Q. (2005): CmeR functions as a transcriptional repressor for the multidrug efflux pump CmeABC in Campylobacter jejuni. Antimicrob Agents Chemother, 49(3): 1067-75.

[57]Cagliero, C.; Maurel, M.-C.; Cloeckaert, A. and Payot, S. (2007): Regulation of the expression of the CmeABC efflux pump in Campylobacter jejuni: identification of a point mutation abolishing the binding of the $C m e \mathrm{R}$ repressor in an in vitro-selected multidrug-resistant mutant. FEMS Microbiol Lett, 267(1): 89-94.

[58]Guo, B.; Wang, Y.; Shi, F.; Barton, Y.-W.; Plummer, P.; Reynolds, D.L.; Nettleton, D.; Grinnage-Pulley, T.; Lin, J. and Zhang, Q. (2008): CmeR functions as a pleiotropic regulator and is required for optimal colonization of Campylobacter jejuni in vivo. J Bacteriol, 190(6): 1879-90.

[59]Lei, H.T.; Shen, Z.; Surana, P.; Routh, M.D.; Su, C.C.; Zhang, Q. and Yu, E.W. (2011): Crystal structures of CmeR-bile acid complexes from Campylobacter jejuni. Protein Sci, 20(4): 712-23.

[60]Lin, J.; Cagliero, C.; Guo, B.; Barton, Y.W.; Maurel, M.-C.; Payot, S. and Zhang, Q. (2005): Bile salts modulate expression of the CmeABC multidrug efflux pump in Campylobacter jejuni. J Bacteriol, 187(21): 7417-24.

[61]Shen, Z.; Pu, X.-Y. and Zhang, Q. (2011): Salicylate functions as an efflux pump inducer and promotes the emergence of fluoroquinolone-resistant Campylobacter jejuni mutants. Appl Environ Microbiol, 77(20): 7128-33.

[62]Hwang, S.; Zhang, Q.; Ryu, S. and Jeon, B. (2012): Transcriptional regulation of the CmeABC multidrug efflux pump and the KatA catalase by Cos $\mathrm{R}$ in Campylobacter jejuni. J Bacteriol, 194(24): 6883-91.

[63]Jeon, B.; Wang, Y.; Hao, H.; Barton, Y.W. and Zhang, Q. (2010): Contribution of CmeG to antibiotic and oxidative stress resistance in Campylobacter jejuni. J Antimicrob Chemother: dkq418.

[64]Holmes, K.; Mulholland, F.; Pearson, B.M.; Pin, C.; McNicholl-Kennedy, J.; 
Ketley, J.M. and Wells, J.M. (2005): Campylobacter jejuni gene expression in response to iron limitation and the role of Fur. Microbiology, 151(1): 243-57.

[65]Palyada, K.; Sun, Y.-Q.; Flint, A.; Butcher, J.; Naikare, H. and Stintzi, A. (2009): Characterization of the oxidative stress stimulon and PerR regulon of Campylobacter jejuni. BMC genomics, 10(1): 481.

[66]Miethke, M.; Klotz, O.; Linne, U.; May, J.J.; Beckering, C.L. and Marahiel, M.A. (2006): Ferri-bacillibactin uptake and hydrolysis in Bacillus subtilis. J Mol Biol, 61(6): 1413-27.

[67]Cirz, R.T.; Jones, M.B.; Gingles, N.A.; Minogue, T.D.; Jarrahi, B.; Peterson, S.N. and Romesberg, F.E. (2007): Complete and SOS-mediated response of Staphylococcus aureus to the antibiotic ciprofloxacin. J Bacteriol, 189(2): 531-9.

[68]Kelley, W.L. (2006): Lex marks the spot: the virulent side of $S O S$ and a closer look at the LexA regulon. Molecular microbiology, 62(5): 1228-38.

[69]Han, J.; Sahin, O.; Barton, Y.-W. and Zhang, Q. (2008): Key role of $M f d$ in the development of fluoroquinolone resistance in Campylobacter jejuni. PLoS Pathog, 4(6): e1000083.

[70]Selby, C.P. and Sancar, A. (1993): Molecular mechanism of transcriptionrepair coupling. SCIENCE-NEW YORK THEN WASHINGTON, 260: 53.

[71]Selby, C.P. and Sancar, A. (1994): Mechanisms of transcription-repair coupling and mutation frequency decline. Microbiological reviews, 58(3): 317-29.

[72]Lehtopolku, M.; Kotilainen, P.; HaanperäHeikkinen, M.; Nakari, U.-M.; Hänninen, M.-L.; Huovinen, P.; Siitonen, A.; Eerola, E.; Jalava, J. and Hakanen, A.J. (2011): Ribosomal mutations as the main cause of macrolide resistance in Campylobacter jejuni and Campylobacter coli. Antimicrob Agents Chemother, 55(12): 5939-41.

[73]Poehlsgaard, J. and Douthwaite, S. (2005): The bacterial ribosome as a target for antibiotics. Nat Rev Microbiol, 3(11): 870-81.

[74]Pfister, P.; Jenni, S.; Poehlsgaard, J.; Thomas, A.; Douthwaite, S.; Ban, N. and Böttger, E.C. (2004): The structural basis of macrolide-ribosome binding assessed using mutagenesis of 23S rRNA positions 2058 and 2059. J Mol Biol, 342(5): 156981.

[75]Qin, S.; Wang, Y.; Zhang, Q.; Zhang, M.; Deng, F.; Shen, Z.; Wu, C.; Wang, S.; Zhang, J. and Shen, J. (2013): Report of ribosomal RNA methylase gene erm (B) in multidrug-resistant Campylobacter coli. J Antimicrob Chemother: dkt492.

[76]Gibreel, A.; Kos, V.N.; Keelan, M.; Trieber, C.A.; Levesque, S.; Michaud, S. and Taylor, D.E. (2005): Macrolide resistance in Campylobacter jejuni and Campylobacter coli: molecular mechanism and stability of the resistance phenotype. $\mathbf{J}$ Antimicrob Chemother, 49(7): 2753-9.

[77]Vacher, S.; Ménard, A.; Bernard, E. and Mégraud, F. (2003): PCR-restriction fragment length polymorphism analysis for detection of point mutations associated with macrolide resistance in Campylobacter spp. J Antimicrob Chemother, 47(3): 1125-8.

[78]Gibreel, A. and Taylor, D.E. (2006): Macrolide resistance in Campylobacter jejuni and Campylobacter coli. J Antimicrob Chemother, 58(2): 243-55.

[79]Ladely, S.R.; Meinersmann, R.J.; Englen, M.D.; Fedorka-Cray, P.J. and Harrison, M.A. (2009): 23S rRNA gene mutations contributing to macrolide resistance in Campylobacter jejuni and Campylobacter coli. Foodborne Pathog Dis, 6(1): 91-8.

[80]Cagliero, C.; Mouline, C.; Cloeckaert, A. and Payot, S. (2006): Synergy between efflux pump CmeABC and modifications in ribosomal proteins $\mathrm{L}_{4}$ and $\mathrm{L}_{22}$ in conferring macrolide resistance in Campylobacter jejuni and Campylobacter coli. J Antimicrob Chemother, 50(11): 3893-6.

[81]Caldwell, D.B.; Wang, Y. and Lin, J. (2008): Development, stability, and molecular mechanisms of macrolide 
resistance in Campylobacter jejuni. J Antimicrob Chemother, 52(11): 3947-54.

[82]Corcoran, D.; Quinn, T.; Cotter, L. and Fanning, S. (2006): An investigation of the molecular mechanisms contributing to high-level erythromycin resistance in Campylobacter. Int $\mathbf{J}$ Antimicrob Agents, 27(1): 40-5.

[83]Skinner, R.; Cundliffe, E. and Schmidt, F. (1983): Site of action of a ribosomal RNA methylase responsible for resistance to erythromycin and other antibiotics. J Biol Chem, 258(20): 12702-6.

[84]Roe, D.E.; Weinberg, A. and Roberts, M.C. (1995): Mobile rRNA methylase genes in Campylobacter (Wotinella) rectus. J Antimicrob Chemother, 36(4): 738-40.

[85]Page, W.J.; Huyer, G.; Huyer, M. and Worobec, E. (1989): Characterization of the porins of Campylobacter jejuni and Campylobacter coli and implications for antibiotic susceptibility. J Antimicrob Chemother, 33(3): 297-303.

[86]Stockdale, A.J.; Beeching, N.J.; Anson, J. and Beadsworth, M. (2016): Emergence of extensive fluoroquinolone resistance in campylobacter gastroenteritis in Liverpool, UK. J Infect, 72(3): 398.

[87]Huyer, M.; Parr, T.; Hancock, R. and Page, W. (1986): Outer membrane porin protein of Campylobacter jejuni. FEMS Microbiol Lett, 37(3): 247-50.

[88]Vaara, M. (1993): Outer membrane permeability barrier to azithromycin, clarithromycin, and roxithromycin in Gram-negative enteric bacteria. J Antimicrob Chemother, 37(2): 354-6.

[89]Logan, S.M. (1984): Structural and antigenic heterogeneity of lipopolysaccharides of Campylobacter jejuni and Campylobacter coli. Infect Immun, 45(1): 210-6.

[90]Jeon, B.; Muraoka, W.; Scupham, A. and Zhang, Q. (2009): Roles of lipooligosaccharide and capsular polysaccharide in antimicrobial resistance and natural transformation of
Campylobacter jejuni. $\mathbf{J}$ Antimicrob Chemother, 63(3): 462-8.

[91]Lomovskaya, O. and Bostian, K.A. (2006): Practical applications and feasibility of efflux pump inhibitors in the clinic - a vision for applied use. Biochem Pharmacol, 71(7): 910-8.

[92]Hannula, M. and Hänninen, M.-L. (2008): Effect of putative efflux pump inhibitors and inducers on the antimicrobial susceptibility of Campylobacter jejuni and Campylobacter coli. J Med Microbiol, 57(7): 851-5.

[93]Lomovskaya, O.; Warren, M.S.; Lee, A.; Galazzo, J.; Fronko, R.; Lee, M.; Blais, J.; Cho, D.; Chamberland, S.; Renau, T.; Leger, R.; Hecker, S.; Watkins, W.; Hoshino, K.; Ishida, H. and Lee, V.J. (2001): Identification and characterization of inhibitors of multidrug resistance efflux pumps in Pseudomonas aeruginosa: novel agents for combination therapy. Antimicrob Agents Chemother, 45(1): 105-16.

[94]Lomovskaya, O. and Zgurskaya, H.I. (2011): Efflux Pumps from Gram-negative Bacteria: From Structure and Function to Inhibition. Emerging Trends in Antibacterial Discovery Part II- 4 Novel Targets and Sources: 77-105.

[95]Kourtesi, C.; Ball, A.R.; Huang, Y.-Y.; Jachak, S.M.; Vera, D.M.A.; Khondkar, P.; Gibbons, S.; Hamblin, M.R. and Tegos, G.P. (2013): Microbial efflux systems and inhibitors: approaches to drug discovery and the challenge of clinical implementation. Open Microbiol J, 7(1).

[96]Cagliero, C.; Mouline, C.; Payot, S. and Cloeckaert, A. (2005): Involvement of the CmeABC efflux pump in the macrolide resistance of Campylobacter coli. $\mathrm{J}$ Antimicrob Chemother, 56(5): 948-50.

[97]Payot, S.; Avrain, L.; Magras, C.; Praud, K.; Cloeckaert, A. and Chaslus-Dancla, E. (2004): Relative contribution of target gene mutation and efflux to fluoroquinolone and erythromycin resistance, in French poultry and pig isolates of Campylobacter coli. Int $\mathbf{J}$ Antimicrob Agents, 23(5): 468-72. 
[98]Askoura, M.; Mottawea, W.; Abujamel, T. and Taher, I. (2011): Efflux pump inhibitors (EPIs) as new antimicrobial agents against Pseudomonas aeruginosa. Libyan J Med, 6(1).

[99]Rodrigues, L.; Machado, D.; Couto, I.; Amaral, L. and Viveiros, M. (2012): Contribution of efflux activity to isoniazid resistance in the Mycobacterium tuberculosis complex. Infection, Genetics and Evolution, 12(4): 695-700.

[100]Lomovskaya, O. and Totrov, M. (2005): Vacuuming the periplasm. J Bacteriol, 187(6): 1879-83.

[101]Mahamoud, A.; Chevalier, J.; AlibertFranco, S.; Kern, W.V. and Pagès, J.-M. (2007): Antibiotic efflux pumps in Gram-negative bacteria: the inhibitor response strategy. J Antimicrob Chemother, 59(6): 1223-9.

[102]Singh, M.; Jadaun, G.; Ramdas, K.S.; Chauhan, V.; Mishra, R.; Gupta, K.; Nair, S.; Chauhan, D.; Sharma, V. and Venkatesan, K. (2011): Effect of efflux pump inhibitors on drug susceptibility of ofloxacin resistant Mycobacterium tuberculosis isolates. Indian J Med Res, 133(5): 535.

[103]Gupta, A.K.; Chauhan, D.; Srivastava, K.; Das, R.; Batra, S.; Mittal, M.; Goswami, P.; Singhal, N.; Sharma, V. and Venkatesan, K. (2006): Estimation of efflux mediated multi-drug resistance and its correlation with expression levels of two major efflux pumps in mycobacteria. J Commun Dis, 38(3): 246.

[104]Rodrigues, L.; Villellas, C.; Bailo, R.; Viveiros, M. and Aínsa, J.A. (2013): Role of the $M m r$ efflux pump in drug resistance in Mycobacterium tuberculosis. J Antimicrob Chemother, 57(2): 751-7.

[105]Tsuruo, T.; Iida, H.; Tsukagoshi, S. and Sakurai, Y. (1981): Overcoming of vincristine resistance in P388 leukemia in vivo and in vitro through enhanced cytotoxicity of vincristine and vinblastine by verapamil. Cancer research, 41(5): 1967-72.
[106]Kristiansen, J.E. and Amaral, L. (1997): The potential management of resistant infections with non-antibiotics. J Antimicrob Chemother, 40(3): 319-27.

[107]Amaral, L.; Martins, M. and Viveiros, M. (2007): Enhanced killing of intracellular multidrug-resistant Mycobacterium tuberculosis by compounds that affect the activity of efflux pumps. J Antimicrob Chemother, 59(6): 1237-46.

[108]Molnar, J.; Hever, A.; Fakla, I.; Fischer, J.; Ocsovski, I. and Aszalos, A. (1996): Inhibition of the transport function of membrane proteins by some substituted phenothiazines in E. coli and multidrug resistant tumor cells. Anticancer research, 17(1A): 481-6.

[109]Ordway, D.; Viveiros, M.; Leandro, C.; Bettencourt, R.; Almeida, J.; Martins, M.; Kristiansen, J.E.; Molnar, J. and Amaral, L. (2003): Clinical concentrations of thioridazine kill intracellular multidrug-resistant Mycobacterium tuberculosis. J Antimicrob Chemother, 47(3): 917-22.

[110]Viveiros, M. and Amaral, L. (2001): Enhancement of antibiotic activity against poly-drug resistant Mycobacterium tuberculosis by phenothiazines. Int J Antimicrob Agents, 17(3): 225-8.

[111]Rajyaguru, J.M. and Muszynski, M.J. (1997): Enhancement of Burkholderia cepacia antimicrobial susceptibility by cationic compounds. J Antimicrob Chemother, 40(3): 345-51.

[112]Amaral, 1.; kristiansen, j. and lorian, v. (1992): Synergic effect of chiorpromazine on the activity of some antibiotics. J Antimicrob Chemother, 30(4): 556-8.

[113]Chan, Y.Y.; Ong, Y.M. and Chua, K.L. (2007): Synergistic interaction between phenothiazines and antimicrobial agents against Burkholderia pseudomallei. J Antimicrob Chemother, 51(2): 623-30.

[114]Bailey, A.M.; Paulsen, I.T. and Piddock, L.J. (2008): RamA confers multidrug resistance in Salmonella enterica via 
increased expression of $a c r \mathrm{~B}$, which is inhibited by chlorpromazine. $\mathrm{J}$ Antimicrob Chemother, 52(10): 3604-11.

[115]Martins, M.; Dastidar, S.G.; Fanning, S.; Kristiansen, J.E.; Molnar, J.; Pages, J.M.; Schelz, Z.; Spengler, G.; Viveiros, M. and Amaral, L. (2008): Potential role of non-antibiotics (helper compounds) in the treatment of multidrug-resistant Gram-negative infections: mechanisms for their direct and indirect activities. Int J Antimicrob Agents, 31(3): 198-208.

[116]Michalak, K.; Wesolowska, O.; Motohashi, N.; Molnar, J. and Hendrich, A. (2006): Interactions of phenothiazines with lipid bilayer and their role in multidrug resistance reversal. Curr Drug Targets, 7(9): 1095-105.

[117]Couto, I.; Costa, S.S.; Viveiros, M.; Martins, M. and Amaral, L. (2008): Efflux-mediated response of Staphylococcus aureus exposed to ethidium bromide. J Antimicrob Chemother, 62(3): 504-13.

[118]Marquez, B. (2005): Bacterial efflux systems and efflux pumps inhibitors. Biochimie, 87(12): 1137-47.

[119]Rodrigues, L.; Wagner, D.; Viveiros, M.; Sampaio, D.; Couto, I.; Vavra, M.; Kern, W.V. and Amaral, L. (2008): Thioridazine and chlorpromazine inhibition of ethidium bromide efflux in Mycobacterium avium and Mycobacterium smegmatis. J Antimicrob Chemother, 61(5): 1076-82.

[120]Sabatini, S.; Kaatz, G.W.; Rossolini, G.M.; Brandini, D. and Fravolini, A. (2008): From phenothiazine to 3-phenyl1, 4-benzothiazine derivatives as inhibitors of the Staphylococcus aureus NorA multidrug efflux pump. J Med Chem, 51(14): 4321-30.

[121]Sikkema, J.; De Bont, J. and Poolman, B. (1994): Interactions of cyclic hydrocarbons with biological membranes. J Biol Chem, 269(11): 80228.

[122]Turina, A.d.V.; Nolan, M.; Zygadlo, J. and Perillo, M. (2006): Natural terpenes: self-assembly and membrane partitioning. Biophys Chem, 122(2): 101-13.

[123]Pinto, A.C.d.V.A.; Witt, L.N.M.; Sá, M.M.d.C.M. and Viana, S.L.R. (2004): Atividade antimicrobiana "in vitro" de extrato alcoólico de própolis. Ciência Rural, 34(1): 159-63.

[124]Sartori, M.R.K. (2005): Atividade antimicrobiana de frações de extratos e compostos puros obtidos das fl ores da Acmela brasiliensis Spreng (Wedelia paludosa)(Astaraceae). Atividade antimicrobiana de frações de extratos e compostos puros obtidos das fl ores da Acmela brasiliensis Spreng (Wedelia paludosa)(Astaraceae).

[125]Nostro, A.; Blanco, A.R.; Cannatelli, M.A.; Enea, V.; Flamini, G.; Morelli, I.; Roccaro, A.S. and Alonzo, V. (2004): Susceptibility of methicillin-resistant staphylococci to oregano essential oil, carvacrol and thymol. FEMS Microbiol Lett, 230(2): 191-5.

[126]Andrade, J.C.; Morais-Braga, M.F.B.; Guedes, G.M.; Tintino, S.R.; Freitas, M.A.; Menezes, I.R. and Coutinho, H.D. (2014): Enhancement of the antibiotic activity of aminoglycosides by alphatocopherol and other cholesterol derivates. Biomedicine \& Pharmacotherapy, 68(8): 1065-9.

[127]Hartog, E.; Menashe, O.; Kler, E. and Yaron, S. (2010): Salicylate reduces the antimicrobial activity of ciprofloxacin against extracellular Salmonella enterica serovar Typhimurium, but not against Salmonella in macrophages. $\mathbf{J}$ Antimicrob Chemother, 65(5): 888-96.

[128]Huff, G.; Huff, W.; Balog, J.; Rath, N. and Izard, R. (2004): The effects of water supplementation with vitamin $\mathrm{E}$ and sodium salicylate $\left(\mathrm{Uni}-\mathrm{Sol}{ }^{\circledR}\right)$ on the resistance of turkeys to Escherichia coli respiratory infection. Avian Dis, 48(2): 324-31.

[129]Ioannides, C.; Stone, A.N.; Breacker, P.J. and Basu, T.K. (1982): Impairment of absorption of ascorbic acid following ingestion of aspirin in guinea pigs. Biochem Pharmacol, 31(24): 4035-8. 
[130]Wood, A.; Baxter, G.; Thies, F.; Kyle, J. and Duthie, G. (2011): A systematic review of salicylates in foods: estimated daily intake of a Scottish population. Mol Nutr Food Res, 55(S1): S7-S14.

[131]Janssen, P.; Hollman, P.; Reichman, E.; Venema, D.P.; van Staveren, W.A. and Katan, M.B. (1996): Urinary salicylate excretion in subjects eating a variety of diets shows that amounts of bioavailable salicylates in foods are low. Am J Clin Nutr, 64(5): 743-7.

[132]Price, C.T.; Lee, I.R. and Gustafson, J.E. (2000): The effects of salicylate on bacteria. Int J Biochem Cell Biol, 32(10): 1029-43.

[133]Bolla, J.-M.; Loret, E.; Zalewski, M. and Pagés, J.-M. (1995): Conformational analysis of the Campylobacter jejuni porin. J bacteriol, 177(15): 4266-71.

[134]Randall, L.; Ridley, A.; Cooles, S.; Sharma, M.; Sayers, A.; Pumbwe, L.; Newell, D.; Piddock, L. and Woodward, M.J. (2003): Prevalence of multiple antibiotic resistance in 443 Campylobacter spp. isolated from humans and animals. J Antimicrob Chemother, 52(3): 507-10.

[135]Helmy, Y.A.; El-Adawy, H. and Abdelwhab, E.M. (2017): A Comprehensive Review of Common Bacterial, Parasitic and Viral Zoonoses at the Human-Animal Interface in Egypt. Pathogens, 6(3): 33.

[136]Pazzaglia, G.; Bourgeois, A.; El Diwany, K.; Nour, N.; Badran, N. and Hablas, R. (1991): Campylobacter diarrhoea and an association of recent disease with asymptomatic shedding in Egyptian children. Epidemiol. Infect, 106(1): 7782.

[137]Putnam, S.D.; Frenck, R.W.; Riddle, M.S.; El-Gendy, A.; Taha, N.N.; Pittner, B.T.; Abu-Elyazeed, R.; Wierzba, T.F.; Rao, M.R. and Savarino, S.J. (2003): Antimicrobial susceptibility trends in Campylobacter jejuni and Campylobacter coli isolated from a rural Egyptian pediatric population with diarrhea. Diagn Microbiol Infect Dis, 47(4): 601-8.

[138]Wasfy, M.O.; Oyofo, B.A.; David, J.C.; Ismail, T.F.; El-Gendy, A.M.; Mohran, Z.S.; Sultan, Y. and Peruski Jr, L.F. (2000): Isolation and antibiotic susceptibility of Salmonella, Shigella, and Campylobacter from acute enteric infections in Egypt. J Health Popul Nutr: 33-8.

[139]El-Mohamady, H.; Abdel-Messih, I.A.; Youssef, F.G.; Said, M.; Farag, H.; Shaheen, H.I.; Rockabrand, D.M.; Luby, S.B.; Hajjeh, R. and Sanders, J.W. (2006): Enteric pathogens associated with diarrhea in children in Fayoum, Egypt. Diagn Microbiol Infect Dis, 56(1): $1-5$.

[140]Omar, N.; Mesalllate, D.; Rizk, M. and El Regal, M.E. (2006): P3. 04 Prevalence and Antimicrobial Susceptibility of Campylobacter Species Isolated from Children Diarrheic Samples. J Hosp Infect, 64: S15.

[141]El-Baky, R.A.; Sakhy, M. and Gad, G. (2014): Antibiotic susceptibility pattern and genotyping of Campylobacter species isolated from children suffering from gastroenteritis. Indian $\mathbf{J}$ Med Microbiol, 32(3): 240.

[142]Girgis, S.A.; Rashad, S.S.; Othman, H.B.; Bassim, H.H.; Kassem, N.N. and El-Sayed, F.M. (2014): Multiplex PCR for identification and differentiation of Campylobacter species and their antimicrobial susceptibility pattern in Egyptian patients. Int $\mathbf{J}$ Curr Microbiol App Sci, 3(4): 861-75.

[143]Hefny, A. (2014): Occurrence, antibiotic resistance and genotyping of $C$. jejuni strains isolated from chickens, their meat and humans Master thesis Bacteriology Dep, Fac Vet Med Banha Univ.

[144]Saad, A.E.M. (2014): Zoonotic Importance of campylobacteriosis at Sharkia Province. Master thesis Zoonoses Dep, Fac Vet Med Zagazig Univ.

[145]Khalil, M.; Khalifa, N.O.; Sobhy, M.M. and Rabie, N.S. (2014): Antimicrobial 
resistance among campylobacter isolates from human and poultry of different localities Egypt. Suez Canal Vet Med J, XIX (2): 207-214.

[146]Hamed, E.A.; AbdelRahman, M.A.; Shalaby, A.G.; Morsy, M.M. and Nasef, S.A. (2016): Antibiotic resistance and polymorphism in the quinolone resistance-determining region of Campylobacter spp. isolated from 1-dayold ducklings. Vet J, 211: 100-3.

[147]Hassanain, N.A. (2011): Antimicrobial resistant Campylobacter jejuni isolated from humans and animals in Egypt. Global Veterinaria, 6 (2): 195-200.

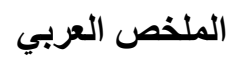

$$
\begin{aligned}
& \text { طرق المقاومة المختلفة لمجموعتي الماكروليد و الكوينولون في الكامبيلوباكتر: مقال }
\end{aligned}
$$

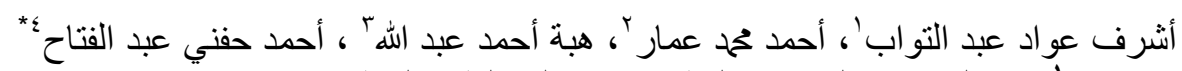

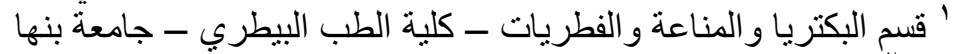

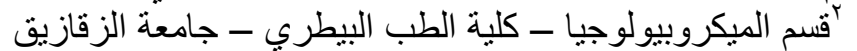

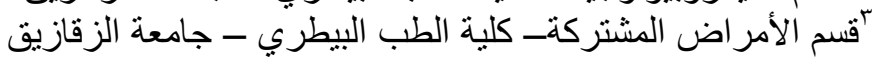

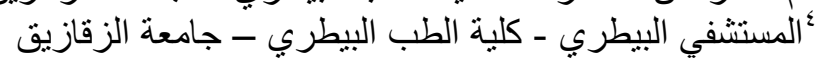

الكامبيلوباكتر تعتبر إحدي مسببات الأمراض الحيوانية المنشأ للإنسان و تعتبر الدواجن خصوصسا الدجاج المصدر

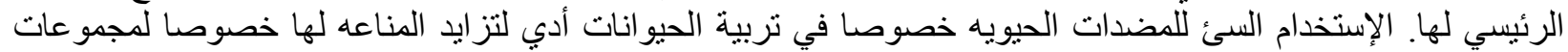

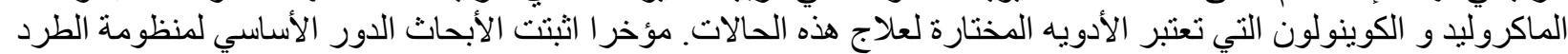

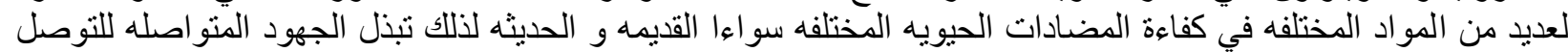

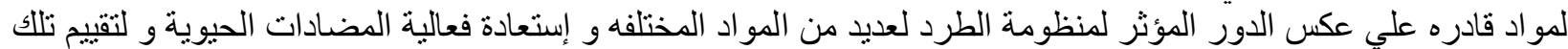

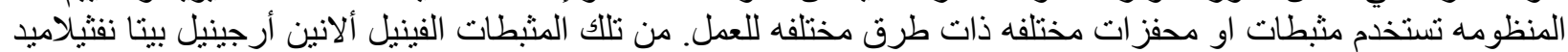

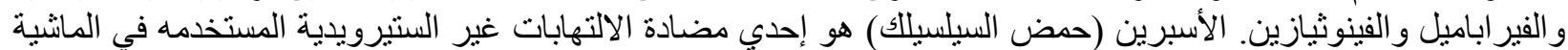

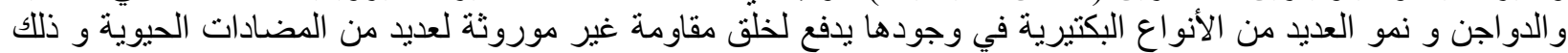

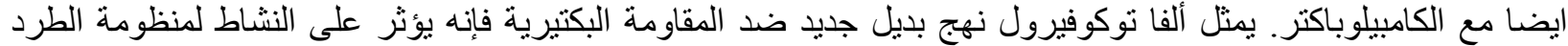

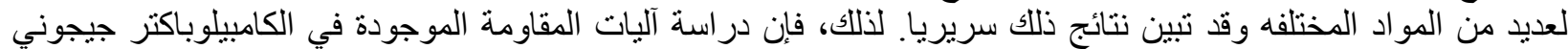

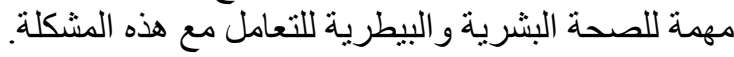

